\title{
INFINITE SERIES FORMULA FOR HÜBNER UPPER BOUND FUNCTION WITH APPLICATIONS TO HERSCH-PFLUGER DISTORTION FUNCTION
}

\author{
Miao-Kun Wang, Song-Liang QIU And Yu-Ming Chu
}

Abstract. In this paper, we find an infinite series formula for the Hübner upper bound function, present the bounds for the Hersch-Pfluger distortion function, and improve the well known results on the quasiconformal Schwarz lemma and the solutions of the Ramanujan modular equations. Besides, the submultiplicative and power submultiplicative properties of the HerschPfluger distortion function are also discussed.

Mathematics subject classification (2010): 33C62, 33E05.

Keywords and phrases: Infinite series formula, Hübner upper bound function, Hersch-Pfluger distortion function, quasiconformal mappings, Ramanujan modular equation.

\section{REFERENCES}

[1] M. Abramowitz, I. A. Stegun (Eds), Handbook of Mathematical Functions with Formulas, Graphs and Mathematical Tables, Dover, New York, 1965.

[2] H. Alzer, K. Richards, On the modulus of the Grötzsch ring, J. Math. Anal. Appl. 432, 1 (2015), $134-141$.

[3] G. D. Anderson, S.-L. QiU, M. K. VAmanamurthy, Elliptic integral inequalities, with applications, Constr. Approx. 14, 2 (1998), 195-207.

[4] G. D. Anderson, S.-L. Qiu, M. K. VAmanamurthy, M. Vuorinen, Generalized elliptic integrals and modular equations, Pacific J. Math. 192, 1 (2000), 1-37.

[5] G. D. Anderson, S.-L. QiU, M. VuORInen, Modular equations and distortion functions, Ramanujan J. 18, 2 (2009), 147-169.

[6] G. D. Anderson, M. K. Vamanamurthy, M. Vuorinen, Distortion functions for plane quasiconformal mappings, Israel J. Math. 62, 1 (1998), 1-16.

[7] G. D. Anderson, M. K. Vamanamurthy, M. Vuorinen, Conformal Invariants, Inequalities, and Quasiconformal Maps, Wiley \& Sons, New York, 1997.

[8] G. D. Anderson, M. K. Vamanamurthy, M. Vuorinen, Topics in special functions II, Conform. Geom. Dyn. 11 (2007), 250-270.

[9] B. A. Bhayo, M. Vuorinen, On generalized complete elliptic integrals and modular functions, Proc. Edinb. Math. Soc. (2) 55, 3 (2012), 591-611.

[10] B. C. Berndt, S. Bhargava, F. G. Garvan, Ramanujan's theories of elliptic functions to alternative bases, Trans. Amer. Math. Soc. 347, 11 (1995), 4163-4244.

[11] Y.-M. CHU, S.-L. QIU, M.-K. WANG, Sharp inequalities involving the power mean and complete elliptic integral of the first kind, Rocky Mountain J. Math. 43, 5 (2013), 1489-1496.

[12] Y.-M. CHU, Y.-F. QIU, M.-K. WANG, Hölder mean inequalities for the complete elliptic integrals, Integral Transforms Spec. Funct. 23, 7 (2012), 521-527.

[13] Y.-M. ChU, M.-K. WANG, Optimal inequalities between harmonic, geometric, logarithmic, and arithmetic-geometric means, J. Appl. Math. 2011 (2011), Article ID 618929, 9 pages.

[14] Y.-M. CHU, M.-K. WANG, Inequalities between arithmetic-geometric, Gini, and Toader means, Abstr. Appl. Anal. 2012 (2012), Article ID 830585, 11 pages.

[15] Y.-M. ChU, M.-K. WANG, Optimal Lehmer mean bounds for the Toader mean, Results Math. 61, 3-4 (2012), 223-229. 
[16] Y.-M. ChU, M.-K. WAng, Y.-P. JiAnG, S.-L. QIU, Concavity of the complete elliptic integrals of the second kind with respect to Hölder means, J. Math. Anal. Appl. 395, 2 (2012), 637-642.

[17] Y.-M. CHU, M.-K. WANG, X.-Y. MA, Sharp bounds for Toader mean in terms of contraharmonic mean with applications, J. Math. Inequal. 7, 2 (2013), 161-166.

[18] Y.-M. CHU, M.-K. WANG, S.-L. QIU, Optimal combinations bounds of root-square and arithmetic means for Toader mean, Proc. Indian Acad. Sci. Math. Sci. 122, 1 (2012), 41-51.

[19] Y.-M. CHU, M. K. WANG, S.-L. QIU, Y.-P. JIANG, Bounds for complete integrals of the second kind with applications, Comput. Math. Appl. 63, 7 (2012), 1177-1184.

[20] Y.-M. ChU, M.-K. WANG, S.-L. QIU, Y.-F. QIU, Sharp generalized Seiffert mean bounds for Toader mean, Abstr. Appl. Anal. 2011 (2011), Article ID 605259, 8 pages.

[21] Y.-M. ChU, M.-K. WANG, Y.-F. QIU, On Alzer and Qiu's conjecture for complete elliptic integral and inverse hyperbolic tangent function, Abstr. Appl. Anal. 2011 (2011), Article ID 697547, 7 pages.

[22] Y.-M. ChU, M.-K. WANG, Y.-F. QIU, X.-Y. MA, Sharp two parameter bounds for the logarithmic mean and the arithmetic-geometric mean of Gauss, J. Math. Inequal. 7, 3 (2013), 349-355.

[23] Y.-M. ChU, T.-H. ZHAO, Convexity and concavity of the complete elliptic integrals with respect to Lehmer mean, J. Inequal. Appl. 2015 (2015), Article 396, 6 pages.

[24] J. Hersch, A. Pfluger, Généralisation du lemme de Schwarz et du principe de la mesure harmonique pour les fonctions pseudo-analytiques, C. R. Acad. Sci. Pairs 234 (1952), 43-45.

[25] O. HÜBNER, Remarks on a paper by Lawrynowicz on quasiconformal mappings, Bull. Acad. Polon. Sci. Sér. Sci. Math. Astronom. Phys., 1970, 18, 183-186.

[26] J. ŁAWRYNOWICZ, Quasiconformal mappings of the unit disc near to the identity, Bull. Acad. Polon. Sci. Sér. Sci. Math. Astronom. Phys. 16, 1968, 771-777.

[27] O. Lehto, K. I. Virtanen, Quasiconformal Mappings in the Plane (2nd ed.), Spring-Verlag, New York-Heidelberg, 1973.

[28] D. Party Ka, Approximation of the Hersch-Pfluger distortion function, Ann. Acad. Sci. Fenn. Ser. A i Math. 18, 2 (1993), 343-354.

[29] S.-L. QIU, Y.-F. QIU, M.-K. WANG, Y.-M. CHU, Hölder mean inequalities for the generalized Grötzsch ring and Hersch-Pfluger distortion functions, Math. Inequal. Appl. 15, 1 (2012), 237-245.

[30] S.-L. QIU, L.-Y. REN, Sharp estimates for Hübner's upper bound function with applications, Appl. Math. J. Chinese Univ. Ser. B 25, 2 (2010), 227-235.

[31] S.-L. Qiu, M. K. Vamanamurthy, M. Vuorinen, Some inequalities for the Hersch-Pfluger distortion function, J. Inequal. Appl. 4, 2 (1999), 115-139.

[32] S.-L. QIU, M. VuORINEN, Submultiplicative properties of the $\varphi_{K}$-distortion function, Studia Math. 117, 3 (1996), 225-242.

[33] S.-L. QIU, M. VUORINEN, Infinite products and the normalized quotients of hypergeometric functions, SIAM J. Math. Anal. 30, 5 (1999), 1057-1075.

[34] Y.-Q. Song, W.-D. JiAng, Y.-M. ChU, D.-D. YAn, Optimal bounds for Toader mean in terms of arithmetic and contraharmonic means, J. Math. Inequal. 7, 4 (2013), 751-757.

[35] M. Vuorinen, Singular values, Ramanujan modular equations, and Landen transformations, Studia Math. 121, 3 (1996), 221-230.

[36] CH.-F. WANG, On the precision of Mori's theorem in Q-mapping, Sci. Record (N.S.) 4 (1960), 329 333.

[37] G.-D. WANG, X.-H. ZhAng, Y.-M. ChU, Inequalities for the generalized elliptic integrals and modular functions, J. Math. Anal. Appl. 331, 2 (2007), 1275-1283.

[38] G.-D. WANG, X.-H. ZHANG, Y.-M. CHU, A power mean inequality involving the complete elliptic integrals, Rocky Mountain J. Math. 44, 5 (2014), 1661-1667.

[39] H. WANG, W.-M. QIAN, Y.-M. ChU, Optimal bounds for Gaussian arithmetic-geometric mean with applications to complete elliptic integral, J. Funct. Spaces 2016 (2016), Article ID 3698463, 6 pages.

[40] M.-K. WANG, Y.-M. CHU, Asymptotical bounds for complete elliptic integrals of the second kind, J. Math. Anal. Appl. 402, 1 (2013), 119-126.

[41] M.-K. WANG, Y.-M. ChU, Y.-P. JiAnG, S.-L. QIU, Bounds of the perimeter of an ellipse using arithmetic, geometric and harmonic means, Math. Inequal. Appl. 17, 1 (2014), 101-111.

[42] M.-K. WANG, Y.-M. CHU, S.-L. QIU, Some monotonicity properties of generalized elliptic integrals with applications, Math. Inequal. Appl. 16, 3 (2013), 671-677.

[43] M.-K. WANG, Y.-M. ChU, S.-L. QIU, Sharp bounds for generalized elliptic integrals of the first kind, J. Math. Anal. Appl. 429, 2 (2015), 744-757. 
[44] M.-K. WANG, Y.-M. ChU, S.-L. QIU, Y.-P. JiAnG, Convexity of the complete elliptic integrals of the first kind with respect to Hölder means, J. Math. Anal. Appl. 388, 2 (2012), 1141-1146.

[45] M.-K. WANG, Y.-M. ChU, S.-L. QIU, Y.-P. JIANG, Bounds for the perimeter of an ellipse, J. Approx. Theory 164, 7 (2012), 928-937.

[46] M.-K. WANG, Y.-M. ChU, Y.-F. QIU, S.-L. QIU, An optimal power mean inequality for the complete elliptic integrals, Appl. Math. Lett. 24, 6 (2011), 887-890.

[47] M.-K. WANG, S.-L. QIU, Y.-P. JIANG, Y.-M. ChU, Generalized Hersch-Pfluger distortion function and complete elliptic integrals, J. Math. Anal. Appl. 385, 1 (2012), 221-229.

[48] ZH.-H. YANG, Y.-M. CHU, A monotonicity property involving the generalized elliptic integral of the first kind, Math. Inequal. Appl. 20, 3 (2017), 729-735.

[49] ZH.-H. YANG, Y.-M. CHU, W. ZHANG, Monotonicity of the ratio for the complete elliptic integral and Stolarsky mean, J. Inequal. Appl. 2016 (2016), Article 176, 10 pages.

[50] ZH.-H. YANG, Y.-M. CHU, W. ZHANG, Accurate approximations for the complete elliptic integral of the second kind, J. Math. Anal. Appl. 438, 2 (2016), 875-888.

[51] ZH.-H. YANG, Y.-M. CHU, X.-H. ZHANG, Sharp Stolarsky mean bounds for the complete elliptic integral of the second kind, J. Nonlinear Sci. Appl. 10, 3 (2017), 929-936.

[52] ZH.-H. YANG, Y.-Q. Song, Y.-M. ChU, Sharp bounds for the arithmetic-geometric mean, J. Inequal. Appl. 2014 (2014), Article 192, 13 pages.

[53] X.-H. Zhang, G.-D. WANG, Y.-M. ChU, S.-L. QIU, Distortion theorems of plane quasiconformal mappings, J. Math. Anal. Appl. 324, 1 (2006), 60-65.

[54] X.-H. Zhang, G.-D. WAng. Y.-M. ChU, Remarks on generalized elliptic integrals, Proc. Roy. Soc. Edinburgh Sect. A 139, 2 (2009), 417-426. 